\title{
多元共治视角下河长制的实践探索与机制创新一以重庆市涪陵 区为例
}

陈双艳 李贵科

长江师范学院

DOI:10.32629/eep.v3i4.765

[摘 要] 河长制是多方利益集团进行权力义务划割的治水制度,多元共治是制度设计的关键。本文聚焦河长制的实践模式及其机制创新等问题, 以重庆市涪陵区河长制推行中的经验和不足为线索,从“政策制定、执行、监督、评估问责” 等方面对涪陵区河长制推行中存在的问题进行分 析,探索影响政策执行有效性的因素,结合史密斯的政策执行模型以多元共治为视角提出改善河长制推行效果的策略,为破解涪陵区河湖治理难 题、促进生态文明建设提供借鉴经验。

[关键词] 河长制；多元共治；涪陵区；史密斯政策执行模型

\section{引言}

河湖共治是构建 “五位一体” 发展布局的重要举措, 河长制是进行河 流治理制度创新。2016年中央印发《关于全面推行河长制的意见》，《意 见》强调了河长制制度在河流治理中的重要地位, 并对河长制实施的战略 目标、主要任务作出部署。中央文件以及各地的实践经验为重庆市涪陵区 河流治理治理工作的推进指明了方向、提供了遵循。涪陵区积极推行河长 制, 在借鉴全国优秀的省、市河长制发展经验, 同时结合自身实际情况和现 实需求下, 推出了 “河库警长制” “智慧河长制” 以及 “人民监督员” “无 人机应用” 这四大创新模式, 成效显著。与此同时, 涪陵区河长制推行体系 也暴露出职能权限不清、监管机制不完善、公民参与意识不强等问题。

1 涪陵区河长制政策执行现状分析

1. 1涪陵区水污染防治工作组织领导体系

\section{三级河长任职表}

\begin{tabular}{|c|c|c|c|}
\hline 级别 & 总河长 & 副总河长 & 河库警长 \\
\hline 区级 & $\begin{array}{c}\text { 区委书记、区委 } \\
\text { 副书记、区长共 } \\
\text { 同担任 }\end{array}$ & $\begin{array}{c}\text { 区政协主席、区 } \\
\text { 人大主任 }\end{array}$ & $\begin{array}{c}\text { 政委、政协、区 } \\
\text { 人大、区政府 }\end{array}$ \\
\hline 镇级 & 镇党委书记 & $\begin{array}{c}\text { 镇委副书记、镇 } \\
\text { 长 }\end{array}$ & $\begin{array}{c}\text { 乡镇街道党政领 } \\
\text { 导 }\end{array}$ \\
\hline 村级 & & & $\begin{array}{c}\text { 村 (社区) 党组 } \\
\text { 织主要负责人 }\end{array}$ \\
\hline
\end{tabular}

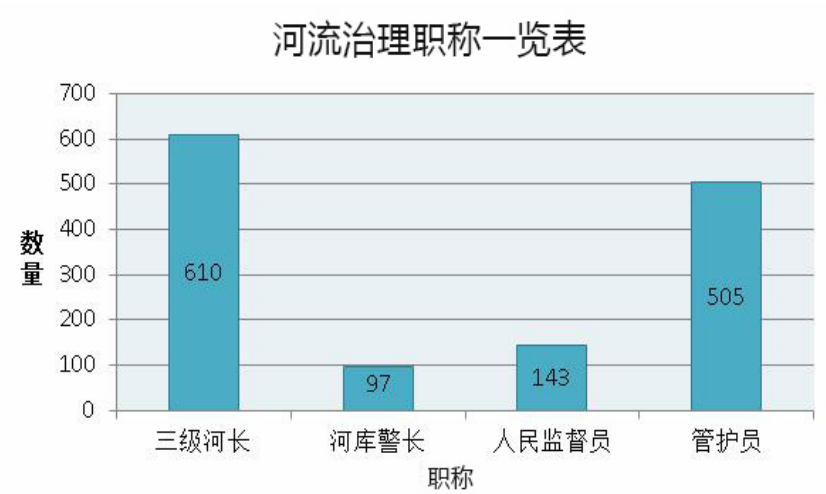

图1. 1涪陵区三级河长任职表图 1.2 涪陵区河长制推行各职务数量分布
2017年以来, 涪陵区为全面推行河长制, 设立河长办公室、全面建立 区、乡镇、村三级河长体系 (如图1.1所示), 在区、乡镇实行 “双总河长” 制, 先后设立了 “人民监督员”、“河库警长” 等职务 (如图1.2所示), 并创 新运用 “智慧河长系统”、“ $5 \mathrm{G}$ 智能无人巡视船”, 为扎实推进水污染防治 工作保驾护航。

\section{2 工作现状及成效}

1.2.1 水污染防治工作中的几大创新点

(1) 构建河库警长体系

建立区、乡、村层面的三级 “河库警长” 体系, 做到河长和警长与河 流一一对应。在公示牌公开河库警长任职信息, 接受公众监督, 实现工作透 明化。制定《河库警长工作制度》, 明确基本工作职责 ${ }^{[1]}$ 。全区河库警长 共计97名, 负责巡查、调解、执法、宣传等工作。

(2) 创新 “智慧河长” 平台

率先建立 “智慧河长” 信息系统, 整合公安、农业多部门的信息和资 源, 有效克服了传统部门资源独享、能力不强等问题。建立信息共享平台, 在日常管理工作、突发情况发生时, 各级组织能迅速统一指挥, 协调资源, 高效化解难题。

\section{（3）设立人民监督员}

向社会聘请河长制人民监督员, 建立人民监督员制度, 营造全民参与 河流治理的氛围。人民监督员们将对管辖范围内河道管治效果进行评价和 上报、提出恰当建议, 提升河长制工作的推行成效。

(4) 应用 $5 G$ 智能无人巡视船

应用智能无人巡视船, 协助河流治理监测工作, 检查结果在后台分析 并以3D图等形式展现。无人船遇到特殊情况时, 可直接采取样本并送回实 验室进行检测, 有效克服传统监测方式无法避免的时效性差、样本采集不 充分等各种问题。

通过对涪陵区河长制在推行过程中的四大创新点可见, 多元共治理念 已逐步应用在创新实践中。

\subsection{2河长制工作成效}

2017年以来, 涪陵区严格按照中央精神、重庆市河流治理管理要求, 稳步推进水污染防治工作, 取得较大成效。长江涪陵段水质得到改善, 乌 江涪陵段水质连续两年为优, 乌江支流以及村级河流水质均符合国家水 质要求达到III类标准、市区饮水水质达标, 乡镇饮用水水质情况得到明 显改善。

(1) 长江乌江污染整治效果显著。对长江乌江排污口进行登记排查, 
已排查登记点位共计553个。督促乌江沿线多家工业、榨菜企业改进废水 处理设备。完成长江乌江码头夏船污水处理, 圆满完成 3 个市考断面水质监 测自动站建设工程。

(2) 完善流域综合整治体系。涪陵区与长寿区等 5 区县合作建立起跨区 县流域保护补偿机制, 并通过协议方式确立下来。扎实推进渠溪河、白洞 溪等5条次级河流日常维护、清沟、巡逻工作。

(3) 加强地区生活污水处理。5座试点乡镇污水处理设备完成改造升级, 城市仅 $5 \%$ 未做到集中处理, 乡镇污水处理率实现大幅度提升达到 $85 \%$, 并采 用全新技术对污水处理设备进行消毒。

(4) 着力处理农村面源污染问题。截至2019年底, 在全区完成了近1.5 万头存栏生猪污染综合治理工程, 大型养殖场废物处理设备实现全覆盖, 逐步推进农作物化肥转型, 非农作物肥料利用率占比降低到 $61 \%$ 。全区确立 肥水养鱼管理条例, 完成三区划定, 加大肥水养殖惩治力度。

\section{2 相关理论与模型}

2.1多元共治理论

多元治理是以法治为基础的多元主体共同治理, 是我国社会治理实践 探索的经验总结, 也是实践中形成的新要求, 多元共治主要包括四大特征: 多元主体, 开放、复杂的共治系统, 以对话、竞争、妥协、合作和集体行动 为共治机制, 以共同利益为最终产出 ${ }^{[2]}$ 。

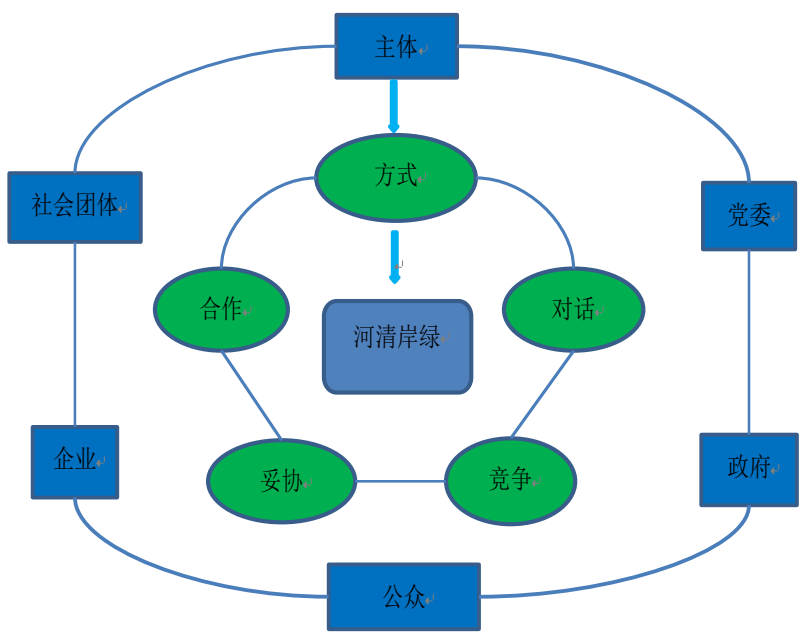

图2.1多元共治理论在河长制中的应用

2. 2 相关模型

2.2.1史密斯政策执行模型

史密斯提出了较为系统的政策执行模型。他认为政策可以被界定为 在旧的机构内设立处理事务的新机构或者改变原来行为模式的行动。政 策从制定到实施, 会对社会中的政策执行者、受众等产生影响, 为避免利 益集团以及相关群众之间产生冲突, 需要采取相应的措施予以规避。如 果在对其进行处理以后, 冲突解决, 就实现制度化, 在必要的时候才给予 回馈。

史密斯将影响政策的重要因素归结为以下四类:

(1) 理想化政策。它包括政策手段、相关群体、具体操作方法等多项 内容。

(2) 执行机构。它通常是指负责政策执行的组织或部门。

(3) 目标群体。即政策作用对象。

(4) 环境因素。包括所有可能影响政策执行的因素, 范围上可以分为 内部和外部, 具体领域可分为政治环境、文化环境、经济环境和社会环 境等。

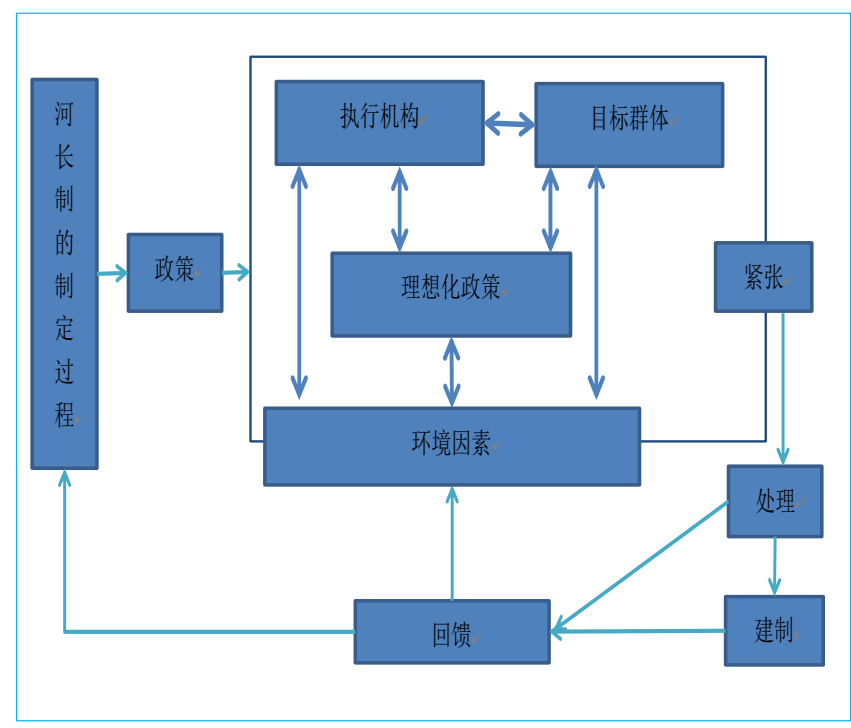

图2.2史密斯政策执行模型

上图为史密斯政策执行模型在涪陵区推行河长制的运行过程, 本文借 助史密斯政策执行模型中四大影响因素对河长制制度 “政策制定、执行、 监督、评估问责” 进行分析, 以构建一个多元协商共治共享治理格局。

\section{3 多元共治视角下涪陵区推行河长制面临的问题及原因分析}

3. 1政策制定体系不完善

首先, 政策内容缺乏一定的合理性, 主要表现在参与主体职责权限的 表述不够细致、协同组织任务分工以及详细职责制定不完善, 从河长的组 织结构体系看, 涪陵区纵向设立了区、乡镇、村级在内的三级河长体系, 横向水利局、环保局等共同参与到河流治理工作中, 涪陵区形成了纵向统 一指挥、横向分工协调的河流治理体系, 但各级人员、各部门的权限没有 通过制度方式明确下来, 权限交叉的情况尚未解决; 其次, 河长制推行过程 中缺乏相关制度保障, 例如涪陵区自2017年开设河长制办公室, 但在2019 年才颁布了《涪陵区河长制工作督查问责制度》, 可见政策制定缺乏科学 性与系统性。

\section{2 理想制度执行与现实存在落差}

首先, 政策执行人员素质不高。面对专业性较强的河流治理工作, 执行 人员的专业素养、领导力、思想道德素质会直接影响其对政策精神的把握, 影响政策执行效果。部分行政执行人员文化知识水平低、专业素质不高, 责任意识不强 ${ }^{[3]}$, 无力完成艰巨任务; 其次, 人力物力不足导致治理力量单 薄。现有编制人员数量不足以应对繁琐的河流治理工作, 同时河长制工作 经费保障不到位, 经费来源渠道单一, 各类社会团体没有充分参与到河流 治理的行列中; 最后, 机构体系设置不合理, 缺乏沟通导致联动性不强。从 各部门抽调人员组成的临时性机构只能应对短期任务且可能造成政出多 门、执行混乱的局面, 协调联动机制不强。同时, 内外部沟通机制不畅通, 机构之间扯皮推诿现象难以避免。

3. 3常态化监督体系不健全

首先, 现有监管力度不够。当前监管体系主要依托于智慧河长系统、人 民监督员、河库警长, 虽在相关方案与制度上对主要监督主体所承担的职责 进行了公示, 但在具体的实践中, 经费不足, 以及工作人员执行力量薄弱等 问题导致以上三大主体很难全方面开展常态化监管。

其次, 多元监管渠道不畅通。当前除去三大主体之外, 人民群众虽然可 以通过电话、信访的方式对违法问题进行举报, 但举报方式较为传统, 另外 发现微信公众号以及网页存在信息更新不及时, 利用率低的问题, 导致群 
众参与的渠道受限。

3. 4 评估问责缺乏有效环境

当前问责主体主要是纪委监委、审计部门以及上级河长, 而问责的 频率、方式、问责的后果等规定各不相同。河长制中河长的权力来自上 级的行政授予, 缺乏法律授权, 大多数地区还是以行政命令、外力强迫为 主推动 ${ }^{[4]}$, 涪陵区亦是如此, 这就导致问责主体权力大, 但职责划分不明, 问责公正性难以保障; 其次法律强制力缺失导致奖惩带来的荣誉性以及 畏惧性被大大减弱, 作为统一利益集团的下级, 将对有限权力的上级缺 乏期待, 使得难以激发体系中各单位以及个人的自发性; 最后问责对象 面对非法定、非系统性的问责机制, 很容易抓住制度漏洞, 从而逐步消化 问责的压力。

\section{4 针对推进涪陵区河长制创新发展的对策}

4. 1 加强联防联控, 优化政策设计

在河长制整个制度设计安排中, 都要秉持联防联控的协商共治思 想。首先, 转变制度存在形式, 提升河长制法治化水平。通过立法方式提 升河长制运行法治化水平, 结合涪陵区本地特色, 制定适宜的法律法规, 以立法形式实现 “河长制” 由政府文件向法律法规的转变; 其次, 优化 具体内容, 提升河长制明确性水平。制度上细化河长的具体职责, 加强河 长对开展河长制工作的认识, 促进河长清晰、高效履职, 巡河日志记载内 容不详不实, 具体问题、配套措施、督办落实等主要内容缺失, 影响到河 长制工作推进成效 ${ }^{[5]}$; 最后, 优化相关保障制度, 系统构建河长制。设计 完善、可操作、合理的问责机制、协调机制、奖励机制。应在明确各执 行机构职责界限的基础上建立系统的协调机制, 在河流治理工作中争取 实现 “ $1+1>2$ ” 的效果。

4. 2 提升政策执行人员素质, 强化河长制执行效果

首先, 要建立各级河长的培训制度。定期开展河长培训, 提升工作人员 的素质。邀请水利专家开设讲座、通过尔雅平台在线教育等方式, 增加河 长制执行人员的水治理常识, 提升执行人员的综合素质能力; 其次, 要优化
人员结构，建立专业人才发展制度。政府部门在条件允许的情况下，适量增 加河长制政策执行人员编制数量, 或者通过从各个职能部门临时抽调人员 组成矩阵结构或挂职、向社会短期聘用等方式, 引进人才。

4.3 创新监督渠道, 建立健全多主体监督机制

首先, 要拓宽社会公众参与渠道。政策推行和创新应该广泛征求公众 的意见, 争取公众的支持, 减轻政府部门负担, 建立公众有奖举报机制, 鼓 励公众 “说实话”; 其次, 要发挥智库、民间组织的专优势, 充分发挥他们 在理论知识普及、参谋咨询、政策结果评估等方面的优势; 最后, 要积极 鼓励社会资本参与, 缓解河流治理工作经费来源渠道单一等问题, 发挥社 会资本的优势, 实现政府与社会优势的互补。

4. 4推进问责机制法定化, 保障有序评估问责

问责机制法定, 将很大程度上有效规范河长制问责机制的问责程 序、问责内容, 彰显法制精神, 破解 “委托一一代理” 带来的异化风险。 但在问责机制法定的设计中, 需要充分调研, 力求寻找最大公约数, 不能 一刀切, 要让问责机制在阳光下运行, 使得河长制长久稳定发展。问责机 制的法定主要在两个环节进行, 一是在具体的问责内容方面, 将涉及重 大社会利益、环境利益的内容纳入问责范围。二是要用法制进行兜底, 既不能因为法律的规定, 让制度过于呆板, 损害各级河长的积极性, 也不 能让制度过于宽松。

\section{[参考文献]}

[1]李敏.涪陵区创新工作举措深入推进河长制工作[J].重庆行政(公 共论坛),2018,19(03):61-63.

[2]武鹏.《基层创新社会治理的建制探索》[D].东南大学,2016.

[3]唐志华.广州流溪河河长制政策执行研究 [D].华南理工大学,2019.

[4]朱玫.论河长制的发展实践与推进[J].环境保护,2017,21(2):58-61.

[5]孙琳.社区教育政策执行的影响因素及优化路径——基于史密斯 模型的分析[J].职教通讯,2019,(17):39-45. 